\title{
REVIEWING ANTIBIOGRAM OF SALMONELLA TYPHI AS BLOOD CULTURE ISOLATE IN A TERTIARY CARE HOSPITAL, KOLKATA- REVERTING SUSCEPTIBILITY PROFILE
}

\author{
Anjum Namhata ${ }^{1}$,Soma Sarkar², Manideepa Sen Gupta ${ }^{3}$ \\ ${ }_{1}^{1}$ Senior Resident, Department of Microbiology, NRS Medical College, Kolkata, West Bengal, India. \\ ${ }^{2}$ Associate Professor, Department of Microbiology, NRS Medical College, Kolkata, West Bengal, India. \\ 3 Professor And HOD, Department of Microbiology, Medical College, Kolkata, West Bengal, India.
}

\begin{abstract}
\section{BACKGROUND}

Enteric fever is still a major contributor to the disease burden in India. According to National Health Profile 2018, a total of 493 deaths occurred in 2017 in India due to typhoid fever. Early diagnosis and treatment with proper drugs are the only option to reduce mortality. After development of resistance to fluoroquinolones (once the most frequently used drugs for treatment of multidrug resistant enteric fever), we are currently left with third generation cephalosporins and azithromycin. But irrational use of these drugs may lead to development of resistance in near future. So, it is time to review re-introduction of the age old first line drugs like ampicillin, chloramphenicol and co-trimoxazole, in the treatment of typhoid fever. The aim of our study was to review the susceptibility pattern of Salmonella Typhi based on their MIC and rational use of antibiotics to prevent further development of MDR strains.
\end{abstract}

\section{METHODS}

In this retrospective study, 4142 blood samples were collected and studied for one-year period. Isolated organisms and their drug susceptibility patterns were analysed based on their MIC.

\section{RESULTS}

Among the 1187 (28.65\%) culture positive isolates, 1.85\% of Salmonella spp. were isolated including 22 Salmonella Typhi and single isolate of Salmonella Paratyphi A. Most of the isolates were from male patients (68.18\%) with less than 20 years of age (77.27\%). Salmonella Typhi showed 100\% sensitivity to ampicillin, chloramphenicol and co-trimoxazole. It also showed $100 \%$ resistance to nalidixic acid and 54.55\% resistance to ciprofloxacin. However, $100 \%$ sensitivity to third generation cephalosporins, carbapenems, colistin and azithromycin was also observed. A single isolate of Salmonella Paratyphi A showed same resistogram as of Salmonella Typhi.

\section{CONCLUSIONS}

Delay in instituting effective antimicrobial treatment results in poor outcome in patients suffering from typhoid fever. As there are variations in the antibiotic susceptibility patterns of Salmonella isolates, periodic monitoring of resistance pattern will remain essential for effective empirical therapy which should correspond with patterns of antimicrobial susceptibility of local Salmonella strains; otherwise irrational use of antibiotics may again cause appearance of MDR strains in the near future.

\section{KEY WORDS}

Salmonella Typhi, MDR, NARST, DCS, Antibiogram

HOW TO CITE THIS ARTICLE: Namhata A, Sarkar S, Gupta MS. Reviewing antibiogram of Salmonella Typhi as blood culture isolate in a tertiary care hospital, Kolkata- reverting susceptibility profile. J. Evolution Med. Dent. Sci. 2019;8(28):2270-2273, DOI: $10.14260 /$ jemds/2019/497

\section{BACKGROUND}

Enteric fever is a potentially fatal multisystemic illness caused primarily by Salmonella enterica, subspecies enterica serovar Typhi and to a lesser extent, related serovars Paratyphi A, B, and C. Enteric fever is a major public health problem causing an estimated between 11 and 21 million cases and 1,28,000 to 1,61,000 typhoid-related deaths occur annually worldwide (WHO 2018).

'Financial or Other Competing Interest': None.

Submission 18-05-2019, Peer Review 30-06-2019,

Acceptance 05-07-2019, Published 15-07-2019.

Corresponding Author:

Dr. Soma Sarkar,

Associate Professor,

Department of Microbiology,

NRS Medical College,

Kolkata, West Bengal,

India.

E-mail: drdssarkar@gmail.com

DOI: $10.14260 /$ jemds $/ 2019 / 497$ 21,190 cases and 493 deaths per year (2018).[1] The classical presentation of the disease includes fever, malaise, diffuse abdominal pain, occasional loose stool and constipation. The presenting signs and symptoms of typhoid fever in children differ significantly from those in adults. Abdominal distension more common in younger children whereas abdominal pain and headache were more common in older children. ${ }^{[2]}$ The ever-changing resistance pattern of these causative agents makes the disease a true therapeutic challenge.

In India, antibiotic resistance has emerged whenever a drug has been widely used for the treatment of enteric fever. After its introduction in 1948, chloramphenicol resistance was seen within 2 years, although the first outbreak in India was not reported until 1972.[3] Subsequent widespread use of amoxicillin resulted in the emergence of TEM1, a plasmid borne $\beta$-lactamase capable of hydrolysing penicillin but not extended-spectrum cephalosporins. Use of co-trimoxazole promoted resistance through sul 1 and sul2 and the dfra7 gene. By the end of the 1980s, multidrug resistant typhoid 
(MDRT), defined as isolates resistant to amoxicillin, cotrimoxazole and chloramphenicol, was raging throughout India. Although there are no countrywide surveillance data from this period, individual studies from all regions of India showed the emergence and rise of MDRT during the late 1980s and 90s.[4-7] After the rise of MDRT, ciprofloxacin became the drug of choice. However, point mutations in the Quinolone Resistance Determining Region (QRDR) of DNA gyrase gave rise to decreased ciprofloxacin susceptibility (DCS), identified in vitro by nalidixic acid resistance. DCS strains were associated with delayed fever clearance and an increase in the rate of complications and clinical failure.[8] Most clinicians now favour azithromycin for uncomplicated disease and ceftriaxone for patients requiring intravenous therapy and this is recommended in the National Treatment Guidelines for Antimicrobial Use in Infectious Diseases, recently published by the National Centre for Disease Control in India (NCDC).[9] Cefixime, an oral third-generation cephalosporin, is also recommended by the NCDC guidelines and the Indian Association of Paediatricians for uncomplicated disease,[10] but is associated with delayed fever clearance times and clinical failure.[11] Similarly, even ceftriaxone resistant strains have been reported from various parts of India.[12] As there are variations in the sensitivity patterns of Salmonella isolates from time to time, continuous monitoring of antibiotic susceptibility pattern of locally prevalent strains is needed and the study was conducted to review the antimicrobial susceptibility of local Salmonella isolates against commonly used drugs.

\section{METHODS}

A retrospective study was done from the laboratory records and relevant data maintained over a period of one year, from April 2018 to March 2019 in a tertiary care hospital. Total 4142 blood samples were collected during the study period from febrile patients admitted in different wards by aseptic measures irrespective of age and sex. Approximately 10-15 $\mathrm{ml}$ of blood was collected from the adult patients and 5-10 ml from paediatric age group as adequate volume of blood is required for culture to become positive. Each blood samples were directly inoculated in BacT/ALERT (bioMerieux System) blood culture bottle. Subcultures were done on MacConkey's agar and Blood agar from the bottles which gave positive signals. All positive growths including nonlactose fermenting colonies were processed for identification, antibiotic susceptibility and MIC values with the help of Vitek2 (bioMerieux System) and interpreted according to Clinical and Laboratory Standards Institute (CLSI) recommendations. To confirm the serotype slide agglutination test with specific antisera was also done. Vitek2 system gave sensitivities of the antibiotics used in typhoid fever with their MIC values except Chloramphenicol and Azithromycin. So, E-test (Hi media, Mumbai, India) strip was used for detection of MIC values of the aforementioned drugs. Clinical history was taken from the patients whose blood culture yield Salmonella spp. to find out the most common presenting symptoms. Clinical features were also studied in different age groups. Data were analysed and expressed in number and percentages.

\section{RESULTS}

Total 4142 blood samples were tested, out of which 1187 (28.65\%) samples were "Culture positive". Coagulase Negative Staphylococcus (CONS) (34.71\%) was most common among the isolates followed by Staphylococcus Aureus (30.92\%), Klebsiella spp. (12.89\%), Escherichia coli (9.43\%), Acinetobacter spp. (6.07\%), Pseudomonas spp. (3.12\%), Salmonella spp. (1.85\%) and Candida spp. (1.01\%) (figure 1). Total 22 (21 Salmonella Typhi and 1 Salmonella Paratyphi A) Salmonella spp. were isolated with moderate male preponderance (68.18\%) and increased $(77.27 \%)$ predisposition in children and young adults $(<20$ yrs.) (Table 1).

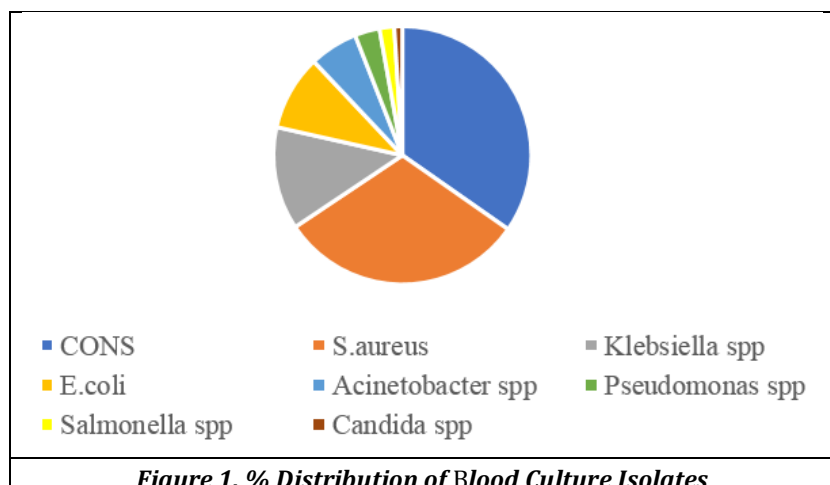

Figure 1. \% Distribution of Blood Culture Isolates

\begin{tabular}{|c|c|c|c|}
\hline Age Group & $<10$ Yrs. & 10-20 Yrs. & 20-30 Yrs. \\
\hline$\%$ of patients & $27.27 \%$ & $50 \%$ & $22.73 \%$ \\
\hline \multicolumn{4}{|c|}{ Table 1. Age Distribution of Patients with Enteric Fever } \\
\hline Age Group & $<10$ Yrs. & 10-20 Yrs. & 20-30 Yrs. \\
\hline Diarrhoea & $68.75 \%$ & $60.0 \%$ & $33.33 \%$ \\
\hline Constipation & $31.25 \%$ & $40.0 \%$ & $66.67 \%$ \\
\hline \multicolumn{4}{|c|}{$\begin{array}{c}\text { Table 2. \% Distribution of G.I. Symptoms with Age of } \\
\text { Enteric Fever Patients }\end{array}$} \\
\hline
\end{tabular}

\begin{tabular}{|c|c|c|c|c|c|c|c|c|c|}
\hline \multirow[t]{2}{*}{ Drugs } & \multicolumn{3}{|c|}{ Sensitive } & \multicolumn{3}{|c|}{$\begin{array}{c}\text { Intermediate SDD= } \\
\text { Susceptible Dose } \\
\text { Dependent }\end{array}$} & \multicolumn{3}{|c|}{ Resistant } \\
\hline & 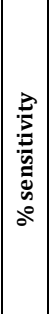 & 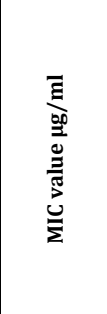 & 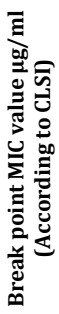 & 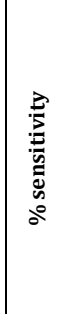 & 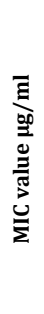 & 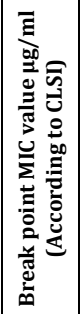 & 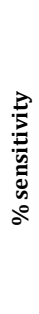 & 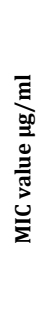 & 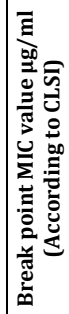 \\
\hline Ampicillin & 100 & $\leq 2$ & $\leq 8$ & 0 & - & 16 & 0 & - & $\geq 32$ \\
\hline $\begin{array}{l}\text { Chloram- } \\
\text { phenicol }\end{array}$ & 100 & $\begin{array}{c}\leq 4 \\
(27.27 \%) \\
\leq 8 \\
(72.73 \%)\end{array}$ & $\leq 8$ & 0 & - & 16 & 0 & - & $\geq 32$ \\
\hline \begin{tabular}{|c|} 
Co-trimoxazole \\
(Trimethoprim- \\
sulphame- \\
thoxazole) \\
\end{tabular} & 100 & $\leq 20$ & $\begin{array}{c}\leq 2 / 3 \\
8\end{array}$ & 0 & - & - & 0 & - & $\geq 4 / 76$ \\
\hline Azithromycin & 100 & $\begin{array}{c}\leq 4 \\
(13.64 \%) \\
\leq 8 \\
(63.63 \%) \\
\leq 16 \\
(22.73 \%)\end{array}$ & $\leq 16$ & 0 & - & - & 0 & - & $\geq 32$ \\
\hline Ceftriaxone & 100 & $\leq 1$ & $\leq 1$ & 0 & - & 2 & 0 & - & $\geq 4$ \\
\hline Cefo-sulbactam & 100 & $\leq 8$ & 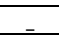 & 0 & - & & 0 & - & - \\
\hline Cefepime & 100 & $\leq 1$ & $\leq 2$ & 0 & - & \begin{tabular}{|c|}
$4-$ \\
$8(\mathrm{SDD})$ \\
\end{tabular} & 0 & - & $\geq 16$ \\
\hline Pip-tazo & 100 & $\leq 4$ & $\begin{array}{c}\leq 16 / \\
4\end{array}$ & 0 & - & \begin{tabular}{|c|}
$32 / 4-$ \\
$64 / 4$ \\
\end{tabular} & 0 & - & $\begin{array}{c}\geq \\
128 / 4\end{array}$ \\
\hline Ertapenem & 100 & $\leq 0.5$ & $\leq 0.5$ & 0 & - & 1 & 0 & - & $\geq 2$ \\
\hline Imipenem & 100 & $\leq 0.25$ & $\leq 1$ & 0 & - & 2 & 0 & - & $\geq 4$ \\
\hline Meropenem & 100 & $\leq 0.25$ & $\leq 1$ & 0 & - & 2 & 0 & - & $\geq 4$ \\
\hline
\end{tabular}




\begin{tabular}{|c|c|c|c|c|c|c|c|c|c|}
\hline Colistin & 100 & $\leq 0.5$ & & 0 & - & _- & 0 & - & \\
\hline Nalidixic Acid & 0 & -- & $\leq 16$ & 0 & - & - & 100 & 32 & $\geq 32$ \\
\hline Ciprofloxacin & 0 & -- & $\leq 0.06$ & 54.55 & $\begin{array}{c}=0.5 \\
(33.33 \%) \\
\leq 0.25 \\
(66.67 \%)\end{array}$ & $\begin{array}{c}0.12- \\
0.5\end{array}$ & 45.45 & $\begin{array}{c}>1 \\
(40.0 \%) \\
>4(60.0 \\
\%)\end{array}$ & $\geq 1$ \\
\hline
\end{tabular}

\begin{tabular}{|c|c|c|c|}
\hline $\begin{array}{c}\text { Ciprofloxacin } \\
\text { MIC } \leq \mathbf{0 . 2 5}\end{array}$ & $\begin{array}{c}\text { Ciprofloxacin } \\
\text { MIC=0.5 }\end{array}$ & $\begin{array}{c}\text { Ciprofloxacin } \\
\text { MIC }>\mathbf{1}\end{array}$ & $\begin{array}{c}\text { Ciprofloxacin } \\
\text { MIC }>\mathbf{4}\end{array}$ \\
\hline $36.36 \%$ & $18.18 \%$ & $18.18 \%$ & $27.27 \%$ \\
\hline \multicolumn{3}{|c|}{ Table 4. MIC Value Distribution of Ciprofloxacin } \\
\hline
\end{tabular}

\begin{tabular}{|c|c|c|c|c|c|}
\hline \multirow{2}{*}{ Parameters } & \multirow{2}{*}{$\begin{array}{c}\text { Present } \\
\text { Study }\end{array}$} & \multicolumn{4}{|c|}{ Other Studies } \\
\hline & & Study 1 & Study 2 & \multicolumn{2}{|c|}{ Study 3} \\
\hline $\begin{array}{l}\text { Proportion of S. } \\
\text { Typhi among } \\
\text { culture positive } \\
\text { isolates in blood }\end{array}$ & $\begin{array}{l}1.85 \% \\
\text { (April } \\
2018- \\
\text { March } \\
2019 \text { ) } \\
\end{array}$ & $\begin{array}{c}20.30 \% \\
\text { Lunguya et } \\
\text { al[13] } \\
(2007-2011) \\
\end{array}$ & $\begin{array}{c}4.47 \% \\
\text { Singh Lavan } \\
\text { et al[14] } \\
(2012-2014)\end{array}$ & \multicolumn{2}{|c|}{$\begin{array}{c}10.3 \% \\
\text { Tack et al[15] } \\
(2007-2017)\end{array}$} \\
\hline Age distribution & $\begin{array}{c}72.72 \% \\
(<20 \text { yrs. }) \\
27.27 \% \\
(>20 \text { yrs. })\end{array}$ & $\begin{array}{c}81 \%(<30 y r s) \\
\text { Sharvani et } \\
\text { al[16] } \\
\text { (Jan-Dec. } \\
2013)\end{array}$ & \begin{tabular}{|c|}
$60 \%(10-$ \\
$19 y r s)$ \\
$32.8 \%$ \\
$(<10 y r s)$ \\
Lunguya et al \\
$(2007-2011)$ \\
\end{tabular} & \multicolumn{2}{|c|}{$\begin{array}{c}56.52 \%(<16 \text { yrs }) \\
43.47 \%(>16 \text { yrs }) \\
\text { Singh Lavan et al } \\
(2012-2014)\end{array}$} \\
\hline Sex distribution & $\begin{array}{c}\text { Male } \\
68.18 \%\end{array}$ & $\begin{array}{c}\text { Male } 63 \% \\
\text { Sharvani } \\
\text { et al } \\
\text { (Jan-Dec } \\
\text { 2013) } \\
\end{array}$ & $\begin{array}{c}\text { Male } 62.5 \% \\
\text { Bhattacharya } \\
\text { et al[17] } \\
(2016)\end{array}$ & \multicolumn{2}{|c|}{$\begin{array}{c}\text { Male } 54.23 \% \\
\text { Dutta \& Afroj et al[18] } \\
\text { (Jan-Dec. 2012) }\end{array}$} \\
\hline \multicolumn{6}{|c|}{$\%$ of Susceptibility of Salmonella spp. to Commonly Used Drugs } \\
\hline & 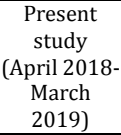 & $\begin{array}{c}\text { Shrirangaraj } \\
\text { et al[19] } \\
\text { (Jan 2012- } \\
\text { June 2013) }\end{array}$ & $\begin{array}{l}\text { Sharvani } \\
\text { et al } \\
\text { (Jan-Dec } \\
2013 \text { ) }\end{array}$ & $\begin{array}{l}\text { Chaudhury } \\
\text { et al[20] } \\
\text { (May 2009- } \\
\text { June 2011) }\end{array}$ & $\begin{array}{c}\text { S.V.Wankhede } \\
\text { et al[21] } \\
\text { (Jan 2015 to } \\
\text { May 2018) }\end{array}$ \\
\hline \begin{tabular}{|c|} 
Chloramphenic \\
ol
\end{tabular} & $100 \%(S)$ & $93.75 \%(S)$ & $95.2 \%(S)$ & $100 \%(S)$ & $100 \%(S)$ \\
\hline Ampicillin & $100 \%(\mathrm{~S})$ & $93.75 \%(\mathrm{~S})$ & $94.6 \%(\mathrm{~S})$ & $90.68 \%(\mathrm{~S})$ & $72.66 \%(\mathrm{~S})$ \\
\hline Co-trimoxazole & $100 \%(\mathrm{~S})$ & $87.5 \%(\mathrm{~S})$ & $95.8 \%(\mathrm{~S})$ & 95-03\%(S) & $100 \%(S)$ \\
\hline Nalidixic acid & $100 \%(\mathrm{R})$ & $100 \%(\mathrm{R})$ & $90.5 \%(\mathrm{R})$ & $74 \%(\mathrm{R})$ & $90.90 \%(\mathrm{R})$ \\
\hline Ciprofloxacin & $\begin{array}{l}54.55 \%(\mathrm{IS}) \\
45.45 \%(\mathrm{R})\end{array}$ & $\begin{array}{l}93.75 \%(\mathrm{IS}) \\
6.25 \%(\mathrm{R})\end{array}$ & $\begin{array}{l}62.2 \%(\mathrm{~S}) \\
37.85(\mathrm{R})\end{array}$ & $54.34 \%(\mathrm{~S})$ & $\begin{array}{l}21.22 \%(\mathrm{~S}) \\
48.48 \%(\mathrm{R}) \\
30.30 \%(\mathrm{IS})\end{array}$ \\
\hline Ceftriaxone & $100 \%(\mathrm{~S})$ & $93.75 \%(S)$ & $97 \%(S)$ & $100 \%(\mathrm{~S})$ & $90.90 \%(S)$ \\
\hline \multicolumn{6}{|c|}{$\begin{array}{l}\text { Table 5. Comparison of Various Parameters Between } \\
\text { Present And other Related Studies }\end{array}$} \\
\hline
\end{tabular}

The common presenting symptoms of patients with enteric fever were fever (100\%), malaise (85\%), anorexia (84\%), headache $(80 \%)$ followed by pain abdomen $(60 \%)$, diarrhoea (52\%), skin rashes (40\%), constipation (27\%) and clinically it was found that adults were more prone to constipation in comparison to children, who usually presented with diarrhoea (Table 2). Other clinical symptoms did not differ with age.

Salmonella Typhi showed 100\% sensitivity to Ampicillin, Chloramphenicol and Co-trimoxazole, the age old first line drugs which eventually lost their efficacy in the previous years (1980s). MIC values of chloramphenicol varied between $4-8 \mu \mathrm{g} / \mathrm{ml}$ with increased $(72.73 \%)$ tendencies to $\leq 8 \mu \mathrm{g} / \mathrm{ml}$. It also showed $100 \%$ sensitivity in third generation Cephalosporins, Carbapenems, Colistin and Azithromycin. The single isolate of Salmonella Paratyphi A showed the same sensitivity pattern. $100 \%$ resistance was seen with Nalidixic acid. Resistance to ciprofloxacin was among $45.45 \%$ isolates and Intermediate sensitivity to ciprofloxacin was seen in $54.55 \%$ isolates (Table 3). According to CLSI 2019 MIC of ciprofloxacin $\leq 0.06 \mu \mathrm{g} / \mathrm{ml}$ is sensitive, 0.12 to $0.5 \mu \mathrm{g} / \mathrm{ml}$ is intermediate-sensitive and $\geq 1 \mu \mathrm{g} / \mathrm{ml}$ is resistant.

As all the isolates have decreased ciprofloxacin susceptibility, determination of MIC value in ciprofloxacin is necessary (Table 4).

\section{DISCUSSION}

In our study among the blood culture positive isolates, 1.85\% was Salmonella spp. and fever was the common clinical presentation (100\%) followed by anorexia (84\%), pain abdomen (60\%). In a study by Sarswat $S$, et al,[22] fever (100\%), anorexia (87.65\%), abdominal pain (75.34\%) and vomiting (47.9\%) were the most common clinical symptoms. We compared our study with others which is shown in the following table (Table 5) to get a comprehensive data on current trends in prevalence of Salmonella spp., age-sex distribution of enteric fever cases and antibiotic profile of Salmonella Typhi.

Azithromycin was $100 \%$ sensitive in our study whereas it was $99.5 \%$ sensitive in a study by Christopher M. Parry et al (2015).[23] In another similar study by Mishra et al (2016) [24] also showed more than $99 \%$ susceptibility to Azithromycin and majority of isolates (75\%) were with MIC values between 4 and $8 \mu \mathrm{g} / \mathrm{ml}$ as in our study ( $>76 \%$ ). In this study there was no Multidrug resistant (MDR) isolates. Similar finding was observed in Pune by S. V. Wankhede, et al [22] and in Puducherry by Bhat K. S. et al.[25] Multidrug resistant (MDR) strains was observed in Delhi (14.9\%) by R Raveeendran et $\mathrm{al}^{[26]}$ and in Karnataka which was even lower (10\%) by Kavita Nagshetty et al[27] while $3.7 \%$ was reported in a study by $\mathrm{S}$ Rai et al[28] and $1.7 \%$ was reported by Sharvani et al on 2013.[17]

\section{CONCLUSIONS}

The present study indicates that the currently prevalent strain in Kolkata is Nalidixic acid resistant $S$. Typhi (NARST) with decreased ciprofloxacin susceptibility (DCS). As no isolates were MDR, reuse of the first line antibiotics can be considered for treating enteric fever cases. To avoid treatment failure, it is necessary to determine MIC levels for ciprofloxacin before use. Third generation cephalosporins still remain a drug of choice for treatment of MDR enteric fever cases. As in some cases, it causes delayed feverclearance or relapse; azithromycin can be considered with third generation cephalosporins. In case of enteric fever, it is advisable to start empirical antibiotic therapy as it decreases the mortality rate of $30 \%$ to as low as $0.5 \%$ [29]. Due to variations in the antibiotic susceptibility pattern of Salmonella isolates, periodic monitoring of resistance pattern will remain essential for deciding rational empirical treatment as overuse or irrational use of antibiotics may again cause emergence of MDR strains.

\section{REFERENCES}

[1] National Health Profile. Ministry of Health \& Family Welfare, Govt. of India. New Delhi: 2018: p. 95.

[2] Walia M, Gaind R, Paul P, et al. Age-related clinical and microbiological characteristics of enteric fever in India. Trans R Soc Trop Med Hyg 2006;100(10):942-8.

[3] Paniker CK, Vimala KN. Transferable chloramphenicol resistance in Salmonella Typhi. Nature 1972;239(5367):109-10.

[4] Arora RK, Gupta A, Joshi NM, et al. Multidrug resistant typhoid fever: study of an outbreak in Calcutta. Indian Pediatr 1992;29(1):61-6.

[5] Dar L, Gupta BL, Rattan A, et al. Multidrug resistant Salmonella Typhi in Delhi. Indian J Pediatr 1992;59(2):221-4. 
[6] Rao RS, Amarnath SK, Sujatha S. An outbreak of typhoid due to multidrug resistant Salmonella Typhi in Pondicherry. Trans R Soc Trop Med Hyg 1992;86(2):204-5.

[7] Sheorey HS, Kaundinya DV, Hulyalkar VS, et al. Multi drug resistant Salmonella Typhi in Bombay. Indian J Pathol Microbiol 1993;36(1):8-12.

[8] Kadhiravan T, Wig N, Kapil A, et al. Clinical outcomes in typhoid fever: adverse impact of infection with nalidixic acid-resistant Salmonella Typhi. BMC Infect Dis 2005;5:37.

[9] National Centre For Disease Control. Directorate General of Health Services Ministry of Health \& Family Welfare, Government of India. National Treatment Guidelines for Antimicrobial Use in Infectious Diseases - Version 1.0 (2016).

[10] Kundu R, Ganguly N, Ghosh TK, et al. IAP Task Force Report: management of enteric fever in children. Indian Pediatr 2006;43(10):884-7.

[11] Cao XT, Kneen R, Nguyen TA, et al. A comparative study of ofloxacin and cefixime for treatment of typhoid fever in children. The Dong Nai Pediatric Center Typhoid Study Group. Pediatr Infect Dis J 1999;18(3):245-8.

[12] Kumar S, Rizvi M, Berry N. Rising prevalence of enteric fever due to multidrug-resistant Salmonella: an epidemiological study. J Med Microbiol 2008;57(Pt 10):1247-50.

[13] Lunguya O, Lejon V, Phoba MF, et al. Salmonella Typhi in the Democratic Republic of The Congo: fluoroquinolone decreased susceptibility on the rise. PLoS Neglected Tropical Diseases 2012;6(11):e1921.

[14] Singh L, Cariappa MP. Blood culture isolates and antibiogram of Salmonella: experience of a tertiary care hospital. Medical Journal Armed Forces India 2016;72(3):281-4.

[15] Tack B, Phoba MF, Van Puyvelde S, et al. Salmonella Typhi from blood cultures in the Democratic Republic of The Congo: a 10-year surveillance. Clinical Infectious Diseases 2019;68(Supplement 2):S130-S7.

[16] Sharvani R, Hemavathi, Dayanand DK, et al. Antibiogram of Salmonella isolates: time to consider antibiotic salvage. Journal of Clinical And Diagnostic Research 2016;10(5):DC06-DC08.

[17] Bhattacharya P, Saha BK, Paul UK, et al. Blood culture in clinically suspected typhoid fever. International Journal of Scientific Study 2017;4(11):53-6.
[18] Afroz H, Hossain M, Md. Fakruddin, et al. Prevalence and antibiotic susceptibility patterns of bloodstream salmonella infections in a tertiary care hospital, Dhaka. Journal of Medical Sciences (Faisalabad) 2013;13(5):360-6.

[19] Srirangaraj S, Kali A, Charles MV. A study of antibiogram of Salmonella enterica serovar Typhi isolates from Pondicherry, India. Australasian Medical Journal 2014;7(4):185-90.

[20] Choudhary A, Gopalkrishnan R, Nambi PS, et al. Antimicrobial susceptibility of Salmonella enterica serovars in a tertiary care hospital in southern India. Indian J Med Res 2013;137(4):800-2.

[21] Wankhede SV, Apurva. Prevalence and antibiogram of salmonella Typhi and para Typhi isolates from a tertiary care hospital. Indian Journal of Basic and Applied Medical Research 2018;7(3):31-8.

[22] Sarswat S, Kumar M, Gupta R. Pediatric nature of enteric fever with emerging antibiogram: a cross sectional study. Int J Pediatr Res 2018;4:039.

[23] Parry CM, Thieu NT, Dolecek C, et al. Clinically and microbiologically derived azithromycin susceptibility breakpoints for Salmonella enterica serovars Typhi and Paratyphi A. Antimicrobial Agents and Chemotherapy 2015;59(5):2756-64.

[24] Misra R, Prasad KN. Antimicrobial susceptibility to azithromycin among Salmonella enterica Typhi and Paratyphi A isolates from India. Journal of Medical Microbiology 2016;65(12):1536-9.

[25] Bhat KS, Anandhalakshmi S, Risitha D, et al. High-level resistance to ciprofloxacin and rising MIC to ceftriaxone and azithromycin among enteric fever isolates from a tertiary care center, Puducherry, India. Int J Curr Microbiol App Sci 2017;6(12):729-36.

[26] Raveendran R, Wattal C, Sharma A, et al. High level ciprofloxacin resistance in Salmonella enterica isolated from blood. Indian J Med Microbiol 2008;26(1):50-3.

[27] Nagshetty K, Channappa ST, Gaddad SM. Antimicrobial susceptibility of Salmonella Typhi in India. J Infect Dev Ctries 2010;4(2):70-3.

[28] Rai S, Jain S, Prasad KN, et al. Rationale of azithromycin prescribing practices for enteric fever in India. Indian J Med Microbiol 2012;30(1):30-3.

[29] Harish BN, Menezes GA. Antimicrobial resistance in typhoidal salmonellae. Indian J Med Microbiol 2011;29(3):223-9. 